\title{
The Chemical Yields Produced by Zero Metal Massive Stars*
}

\author{
Marco Limongi ${ }^{1}$ and Alessandro Chieffi ${ }^{1,2}$ \\ 1 Osservatorio Astronomico di Roma, Via Frascati 33, Monteporzio Catone (Roma), \\ Italy, I-00040 \\ marco@mporzio.astro.it \\ ${ }^{2}$ Istituto di Astrofisica Spaziale (CNR), Via Fosso del Cavaliere, Roma, Italy, I-00133 \\ achieffi@ias.rm.cnr.it
}

\begin{abstract}
In this review we compare the three existing sets of theoretical yields of zero metal massive stars available in the literature. We also show how each of these three different sets of yields fits the element abundance ratios observed in the extremely metal poor star CD $38^{\circ} 245$. We find that, at present, no theoretical set of yields of zero metal massive stars is able to satisfactorily reproduce the elemental ratios $[\mathrm{X} / \mathrm{Fe}]$ of this star.
\end{abstract}

Keywords: stars: evolution — nucleosynthesis — supernovae: general — stars: abundances — Galaxy: formation

\section{Introduction}

The astrophysical relevance of the first generation of massive stars is certainly connected to the chemical enrichment of the primordial interstellar medium. In fact, current Big Bang theories predict that no metals were produced in a significant amount by the Big Bang nucleosynthesis. If we couple this information with the evidence that, at present, metals do exist in the universe and with the current belief that metals are mainly synthesised in stars, we cannot escape the conclusion that at a certain point in the evolution of the universe, zero metal stars did form and that the more massive ones were the first to enrich the pristine material. In spite of this astrophysical relevance only few papers discuss the evolution and nucleosynthesis of zero metallicity massive stars. Woosley \& Weaver (1995, WW95 hereafter) presented the yields of massive stars in the range $13-40 \mathrm{M}_{\odot}$ for five initial metallicities, namely, $\mathrm{Z}=0,0.001,0.01,0.1,1$

*Invited Talk, Annual Conference of the Astronomical Society of Australia, Lorne, 2-4 July, 2001. 
$\mathrm{Z}_{\odot}$, discussing the dependence of the yields on the initial mass and metallicity. By the way let us remind the reader that the yield of any given isotope is defined as the mass in solar masses of that isotope ejected by the star. Chieffi, Limongi, Straniero, \& Dominguez presented and discussed the evolutionary properties, the explosions and the yields of zero metal stars in the range $15-80 \mathrm{M}_{\odot}$ in a series of papers in the last few years (Limongi, Straniero \& Chieffi 2000; Chieffi et al. 2001a, b; Limongi et al. 2001; Limongi \& Chieffi 2001). Finally Umeda \& Nomoto (2002, UN02 hereafter) have recently published the yields of zero metal stars in the range $13-30 \mathrm{M}_{\odot}$.

The first aim of this paper is to compare these three sets of computations and to underline differences and similarities among them.

The second one is that of using these theoretical yields to fit the surface chemical composition of extremely metal poor low mass stars. Such a direct comparison is possible because these stars probably formed in an environment enriched by just the first generation of stars. Hence they give us a unique opportunity of observing directly the ejecta of a single stellar generation and not the complex superimposition of many generations of stars of different metallicity (as happens when looking at stars of higher metallicity). Moreover, recent sets of observational data (McWilliam et al. 1995; Ryan, Norris, \& Beers 1996) have shown that below $[\mathrm{Fe} / \mathrm{H}] \simeq-2.5$ there exists a significant star to star scatter in the observed element abundance ratios. This scatter has been interpreted as a signature of the fact that these stars formed in a highly inhomogeneous medium enriched by very few supernovae (Auduze \& Silk 1995). In this scenario, each primordial cloud was enriched by just one supernova (or, at most, a mixture of two to three SN II) so that the low mass stars of the second generation could preserve, up to the present time, the chemical composition of matter enriched by a single zero metal type II supernova. CD $38^{\circ} 245$ is one of the most metal poor stars presently known and it is probably a good candidate for being such a second generation star. In this paper we intend to discuss mainly the method we intend to adopt to analyse these very metal poor stars and hence we will discuss just the quoted star; a complete analysis of the full sample of the very metal poor stars presently known is in preparation and will be presented shortly.

\section{Comparison Between the Existing Sets of Yields Produced by Zero Metal Massive Stars}

The final chemical composition of the ejecta of a type II supernova is the result of the combined effect of the pre-supernova evolution and of the passage of the shock wave through the mantle of the star during the explosion.

Figure 1 shows the chemical composition left by the passage of the shock wave in a $15 \mathrm{M}_{\odot}$ zero metallicity model taken as a representative case. The $\mathrm{x}$ axis refers to the mass coordinate; the black dots on the upper $\mathrm{x}$ axis in each panel mark the zones heated up to a maximum temperature of 5, 4, 3.3, 2.1, and 1.9 billion degrees during the explosion. These zones are the ones that undergo complete explosive Si burning, incomplete explosive Si burning, explosive O burning, explosive Ne burning, and ex- 

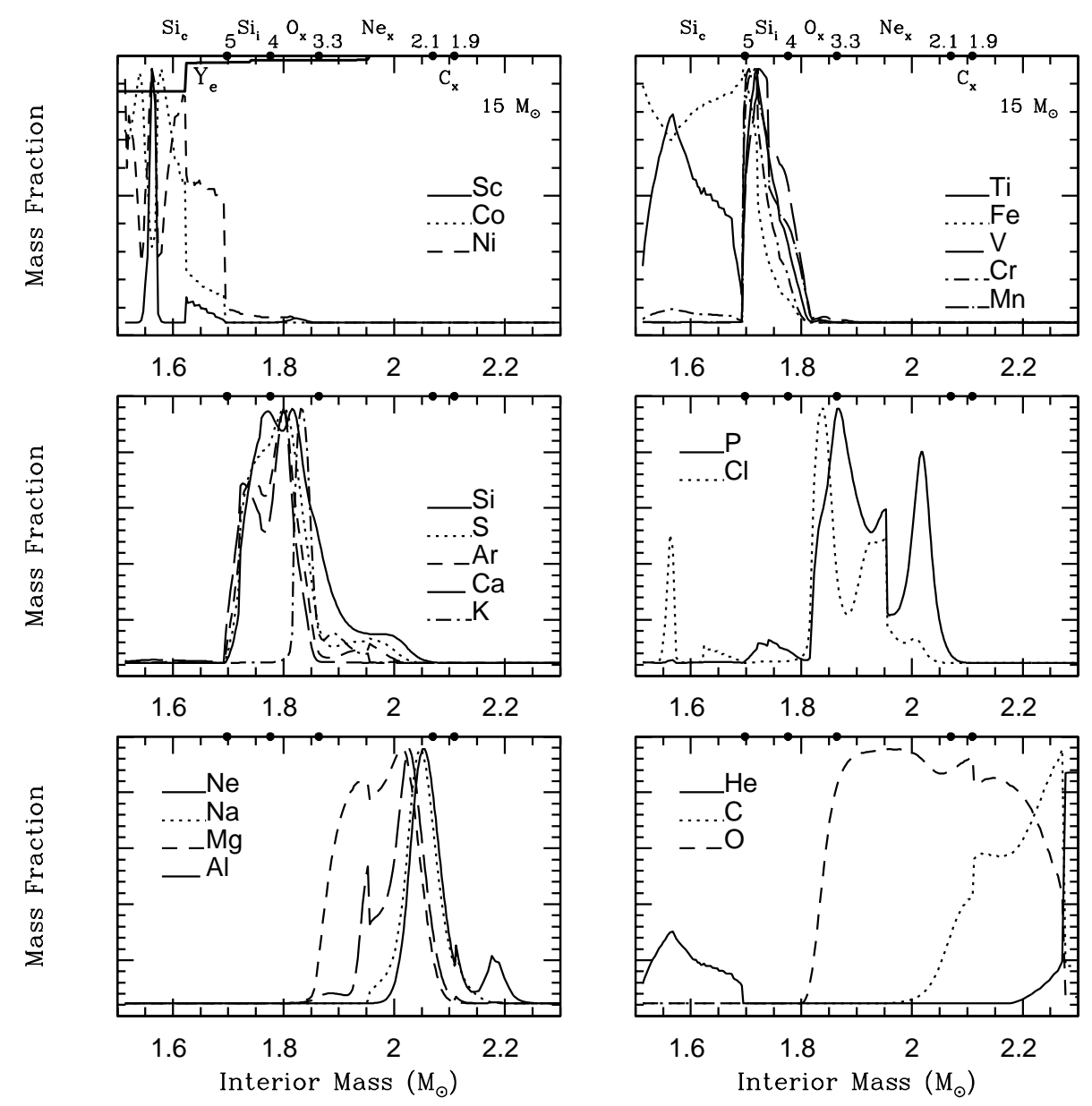

Figure 1: Chemical composition left by the passage of the shock wave in a $15 \mathrm{M}_{\odot}$ model. See text for more details.

plosive $\mathrm{C}$ burning respectively. The zones more external in mass are left untouched by the explosion. The various elements are plotted in the same graph but using different limits for the y axis. Figure 1 clearly shows that each element is produced in a well defined zone of the star after the explosion, so that they can be divided into different groups depending on their production site. In particular we can identify the following groups: (1) $\mathrm{Sc}\left({ }^{45} \mathrm{Sc},{ }^{45} \mathrm{Ca}\right)$, $\mathrm{Co}\left({ }^{59} \mathrm{Co}\right)$, and $\mathrm{Ni}\left({ }^{58} \mathrm{Ni}\right)$ are produced by explosive complete Si burning; (2) $\mathrm{Ti}\left({ }^{48} \mathrm{Ti}\right)$ and $\mathrm{Fe}\left({ }^{56} \mathrm{Fe}\right)$ are produced by a combination of complete and incomplete explosive Si burning; (3) $\mathrm{Cr}\left({ }^{52} \mathrm{Fe}\right), \mathrm{V}\left({ }^{51} \mathrm{Cr}\right)$, and $\mathrm{Mn}\left({ }^{55} \mathrm{Co}\right)$ are produced only by incomplete explosive Si burning; (4) Si $\left({ }^{28} \mathrm{Si}\right), \mathrm{S}\left({ }^{32} \mathrm{~S}\right), \mathrm{Ar}\left({ }^{36} \mathrm{Ar}\right)$, and $\mathrm{Ca}\left({ }^{40} \mathrm{Ca}\right)$ are produced by a combination of incomplete explosive Si burning and explosive O burning; $(5) \mathrm{K}\left({ }^{39} \mathrm{~K}\right)$ is the only element produced exclusively by explosive O burning; (6) $\mathrm{Ne}\left({ }^{20} \mathrm{Ne}\right), \mathrm{Na}\left({ }^{23} \mathrm{Na}\right), \mathrm{Mg}\left({ }^{24} \mathrm{Mg}\right), \mathrm{Al}\left({ }^{27} \mathrm{Al}\right), \mathrm{P}\left({ }^{31} \mathrm{P}\right)$, and $\mathrm{Cl}\left({ }^{35} \mathrm{Cl}\right.$, $\left.{ }^{37} \mathrm{Ar}\right)$ are produced in the $\mathrm{C}$ convective shell during the hydrostatic evolution and then partially modified during the explosion by explosive $\mathrm{C} / \mathrm{Ne}$ burning; (7) $\mathrm{He}\left({ }^{4} \mathrm{He}\right), \mathrm{C}$ 
$\left({ }^{12} \mathrm{C}\right), \mathrm{N}\left({ }^{14} \mathrm{~N}\right), \mathrm{O}\left({ }^{16} \mathrm{O}\right)$, and $\mathrm{F}\left({ }^{19} \mathrm{~F}\right)$ are produced during the hydrostatic evolution and left untouched by the explosion. Elements pertaining to the first two groups depend significantly on the location of the mass cut, i.e. the mass coordinate which separates the remnant from the ejecta, because they are produced in the more internal zones. By the way, the mass cut is still a highly uncertain quantity due to the lack of self consistent models leading to a successful explosion for type II supernovae. All the other elements are not affected by the exact location of the mass cut.
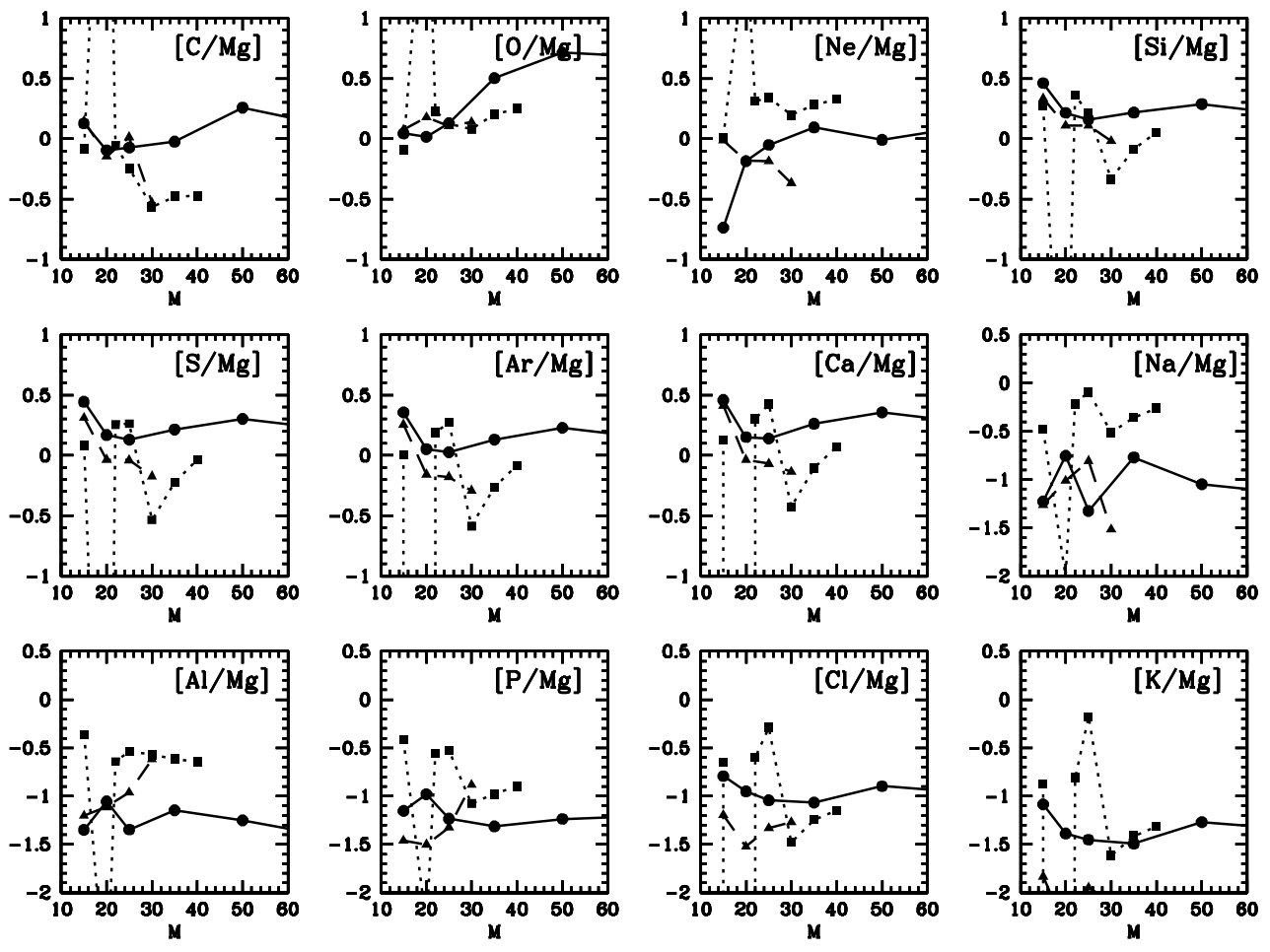

Figure 2: Trend with the mass of the $[\mathrm{X} / \mathrm{Mg}] \log$ ratios obtained by using the three sets of theoretical yields: LC01 (filled circles connected by the solid line); WW95 (filled squares connected by the dotted line); UN02 (filled triangles connected by the dashed line).

Figure 2 shows the trend with the mass of the $[\mathrm{X} / \mathrm{Mg}]\left(\equiv \log (\mathrm{X} / \mathrm{Mg})-\log (\mathrm{X} / \mathrm{Mg})_{\odot}\right)$ $\log$ ratios for the elements that are only marginally influenced by the location of the mass cut. The elements are ordered on the basis of their production site, i.e. the first three panels in the first row refer to the elements produced by hydrostatic burning (i.e. $\mathrm{C}, \mathrm{O}$, and $\mathrm{Ne}$ ); the next four panels refer to elements produced by both incomplete explosive Si and explosive O burning (i.e. Si, S, Ar, and Ca); the following four panels refer to elements produced during the hydrostatic evolution of the stars in the $\mathrm{C}$ convective shell and then partially modified by the explosion (i.e. $\mathrm{Na}, \mathrm{Al}, \mathrm{P}$, and $\mathrm{Cl}$ ); the last panel refers to the single element produced by explosive $\mathrm{O}$ burning, i.e. K. The filled circles connected by a solid line refer, in each panel, to our computations (see Tables 1-6, LC01 hereafter), the filled squares connected by a dotted line refer to the 
yields computed by WW95 (their case C if present), and the filled triangles connected by a dashed line to the yields by UN02. Note that the yields produced by the $20 M_{\odot}$ computed by WW95 are largely altered by the presence of a very extended fall back: this occurrence explains the presence of a 'spike' in this figure and in the following ones. Instead of comparing the yields (in solar masses) ejected by any stellar model, we preferred to compare a quantity that can be directly observed in real stars. We chose the $[\mathrm{X} / \mathrm{Mg}] \log$ ratios because $\mathrm{Mg}$ does not depend on the mass cut; it has a rather strong dependence on the initial mass and is also well determined observationally. All the panels in Figure 2 show that the yields computed by the three groups differ significantly. Since the final abundances of these elements depend mainly on the pre-supernova evolution, it is clear that there is some basic difference in the computation of the evolution of these stars (e.g. treatment of convection, ${ }^{12} \mathrm{C}(\alpha, \gamma){ }^{16} \mathrm{O}$ rate and so on). Unfortunately it is not easy to understand where these differences come from because neither WW95 nor UN02 published any detail (up to now) about their pre-supernova models. There are however a few general comments about the yields, and their trends, worth mentioning. First of all, both our and UN02 yields show a more or less continuous dependence on the mass while the WW95 yields show a rather scattered behaviour in which it is not easy to identify a clear dependence on the mass. Second, both WW95 and UN02 predict [O/Mg] of the order of zero over all the mass intervals they explore, while we predict a trend of this ratio with the initial mass which reaches a maximum value of the order of 0.7 dex; this well defined difference could constitute a good observational check for the models. A further consideration worth noting is the behaviour of the four $\alpha$ elements $\mathrm{Si}, \mathrm{S}, \mathrm{Ar}$, and $\mathrm{Ca}$ : though the three groups predict different yields, within each set of computations all four elements show exactly the same dependence on the initial mass. This is a consequence of the fact that these four elements are strongly coupled to each other because they are produced by the same explosive burning: hence their internal ratios (e.g. [Si/S], [S/Ca], [Ar/Si] and the like) are largely independent of the mass, the initial chemical composition, and the author. By the way, let us remind the reader also that the thermonuclear supernovae produce these four elements in the same relative proportions: this is simply due to the fact that the physical conditions in which these four elements are produced are very similar in the thermonuclear and core collapse supernovae (i.e. the incomplete explosive Si burning and explosive $\mathrm{O}$ burning in an environment only marginally neutronised). Let us eventually note that WW95 predict a much larger ratio for the odd elements, $\mathrm{Na}, \mathrm{Al}, \mathrm{P}$, than we and UN02 do.

Figure 3 shows the trend with the initial mass of the elements which are produced by the complete and incomplete explosive Si burning. In this case the adopted reference element is Fe. These elements are produced in the deep interior of the star hence their yields will largely depend on the mass cut. Since this is a very uncertain parameter, we decided to compute yields for various values of the mass cut. The solid, dotted, and short dashed lines in the first row of Figure 3 show our predictions for three different choices of the mass cut: the solid and dotted lines are obtained by assuming that all stars eject an amount of ${ }^{56} \mathrm{Ni}$ equal to, respectively, $0.01 M_{\odot}$ and $0.1 M_{\odot}$. The dashed line, on the other hand, has been obtained by imposing the mass cut to coincide with 

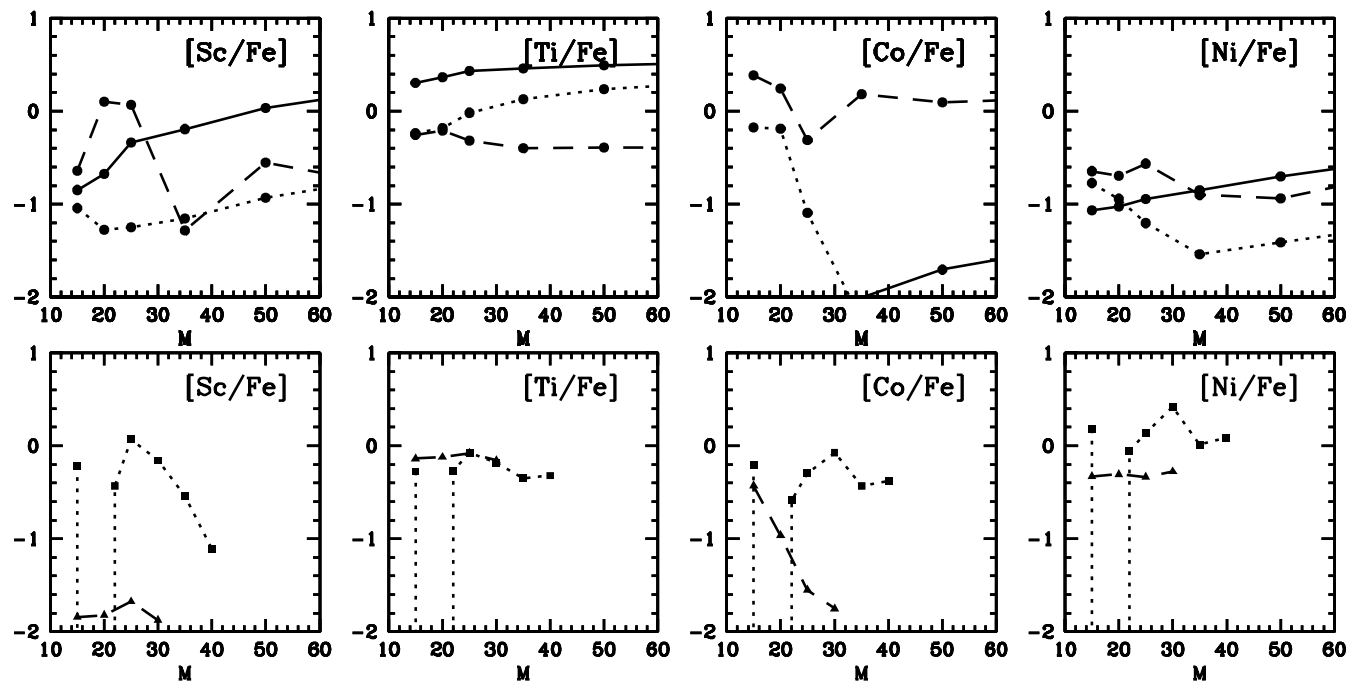

Figure 3: Trend with the mass of [Sc, Ti, Co,Ni/Fe] log ratios for the three sets of yields. The LC01 yields (filled circles) are plotted in the upper panels for three different values of the ${ }^{56} \mathrm{Ni}$ ejected, i.e. $0.01 \mathrm{M}_{\odot}$ (solid line), $0.1 \mathrm{M}_{\odot}$ (dotted line) and the one obtained when the mass cut coincides with the iron core (dashed line). The WW95 and UN02 yields are plotted in the lower panels; the filled squares connected by the dotted line refer to the WW95 yields while the filled triangles connected by the dashed line refer to the UN02 yields.

the Fe core mass for each star in the sample. Since both the generic element (Sc, $\mathrm{Ti}, \mathrm{Co}$, or $\mathrm{Ni}$ ) and the $\mathrm{Fe}$ depend on the mass cut, even a very large change in the amount of ${ }^{56} \mathrm{Ni}$ ejected does not lead to extreme changes in these ratios. [Sc/Fe] shows a behaviour which depends on the mass cut but remains in any case within the range $-1.3 \leq[\mathrm{Sc} / \mathrm{Fe}] \leq 0.1$ dex. Also the range of values for $[\mathrm{Ti} / \mathrm{Fe}]$ remains confined within 1 dex, i.e. between 0.5 and -0.4 for any choice of the mass cut. [Ni/Fe] shows a similar behaviour as well, and it ranges between -0.6 and -1.6 at most. $[\mathrm{Co} / \mathrm{Fe}]$ is the only exception since it shows a very strong dependence on the mass cut. The solid and dotted lines in the second row of Figure 3 represent, respectively, the WW95 and UN02 predictions. Both these groups did not provide yields for different choices of the mass cut so that it is not possible to show the dependence of their result on the mass cut. The $[\mathrm{Sc}, \mathrm{Ti}, \mathrm{Co} / \mathrm{Fe}]$ predicted by WW95 are compatible with our values in the sense that, at least, they fall within the range of possible values we predict, while their predictions for $[\mathrm{Ni} / \mathrm{Fe}]$ fall outside the range of values we obtain. UN02 predict $[\mathrm{Sc} / \mathrm{Fe}]$ and $[\mathrm{Co} / \mathrm{Fe}]$ very low but $[\mathrm{Ti} / \mathrm{Fe}]$ and $[\mathrm{Ni} / \mathrm{Fe}]$ in close agreement with WW95.

Figure 4 shows the behaviour of the three elements which are produced by the incomplete explosive Si burning. Also in this case the first row refers to the yields obtained for the three different choices of the mass cut. The solid and dotted lines refer to the case in which all stars eject an amount of ${ }^{56} \mathrm{Ni}$ equal to, respectively, $0.01 M_{\odot}$ 

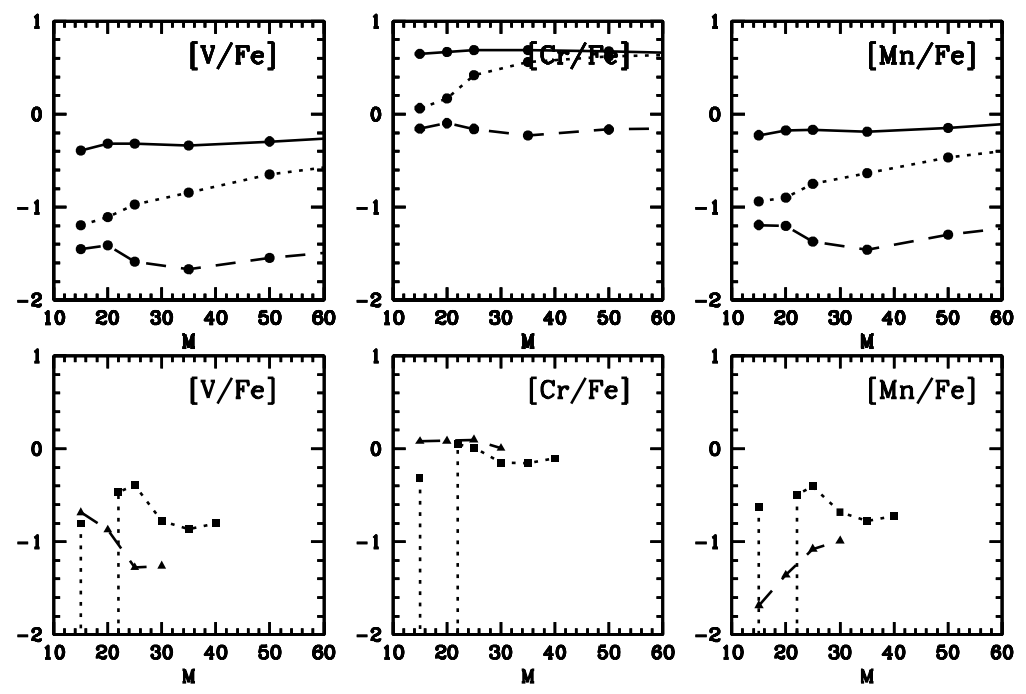

Figure 4: Trend with the mass of $[\mathrm{V}, \mathrm{Cr}, \mathrm{Mn} / \mathrm{Fe}] \log$ ratios for the three sets of yields. The LC01 yields (filled circles) are plotted in the upper panels for three different values of the ${ }^{56} \mathrm{Ni}$ ejected, i.e. $0.01 \mathrm{M}_{\odot}$ (solid line), $0.1 \mathrm{M}_{\odot}$ (dotted line), and the one obtained when the mass cut coincides with the iron core (dashed line). The WW95 and UN02 yields are plotted in the lower panels; the filled squares connected by the dotted line refer to the WW95 yields while the filled triangles connected by the dashed line refer to the UN02 yields.

and $0.1 M_{\odot}$, while the dashed line refers to the case in which the mass cut coincides with the Fe core mass. Though the three ratios depend on the adopted mass cut, we can identify, for each panel, a permitted and a forbidden region. A comparison with the WW95 and UN02 predictions (shown in the second row of Figure 4) shows that there is a generic 'compatibility' in the sense that their data fall within our permitted region.

\section{Comparison Between Theoretical Yields and Ob- servational Data}

The usual technique adopted to compare the observed and the predicted $[\mathrm{X} / \mathrm{Fe}]$ consists in shifting vertically the theoretical predictions until a best fit to the data is obtained. This procedure corresponds (in practice) to an artificial changing of the amount of Fe ejected by the star after the explosion. Such a procedure is essentially correct if it is applied to elements which do not depend on the location of the mass cut while it may be completely wrong if applied to elements whose yields depend on it. The reason is that, in general, if we take the ejecta of a given massive star, the relative scaling of all the various elements is not necessarily preserved by changing the location of the mass 
cut. In particular, the elements may be divided in two groups: the first one (formed by elements from $\mathrm{C}$ to $\mathrm{Ca}$ ) includes all the elements which (presumably) are not largely affected by the uncertainty in the mass cut location. Hence, a changing of the mass cut will simply shift simultaneously the $[\mathrm{X} / \mathrm{Fe}]$ of these elements by the same amount without modifying their relative abundances. The second one (formed by elements from $\mathrm{Sc}$ to $\mathrm{Ni}$ ) includes elements which strongly depend on the location of the mass cut. In this case changing this parameter will not preserve the relative scaling of the $[\mathrm{X} / \mathrm{Fe}]$ of these elements since both the $\mathrm{X}_{\mathrm{s}}$ and the Fe depend (not necessarily in the same way) on it. It is therefore clear that a 'proper' choice of the mass cut is crucial in this comparison. Since we are assuming that these metal poor stars formed in an environment enriched by just one supernova, once the exploding mass has been fixed, we can (almost always) directly derive the amount of Fe ejected by requiring the fit to a given observed $[\mathrm{X} / \mathrm{Fe}] \log$ ratio. We chose to fit the observed $[\mathrm{Mg} / \mathrm{Fe}]$. Of course, the amount of Fe determined in this way will depend on the mass of the exploding star because the amount of $\mathrm{Mg}$ itself is a function of the initial mass.

Just as an example of the method we will present, in the following, the comparison between the three existing sets of yields and the element abundance pattern observed in the star CD $38^{\circ} 245([\mathrm{Fe} / \mathrm{H}]=-4.01)$ which is the most metal poor star in the McWilliam et al. (1995) database.

Figure 5 shows the fit to CD $38^{\circ} 245$ with our theoretical yields. The filled squares represent the observed abundances while the filled dots refer to the predicted abundances. The six panels show the comparison between the quoted star and the ejecta of different stellar masses (once the mass cut for each stellar mass has been chosen to fit the observed $[\mathrm{Mg} / \mathrm{Fe}]$ ). Since the amount of $\mathrm{Mg}$ increases significantly with the mass of the star, the amount of ${ }^{56} \mathrm{Ni}$ ejected increases with the initial mass. The six panels show that, once $[\mathrm{Mg} / \mathrm{Fe}]$ is fitted, $[\mathrm{Al} / \mathrm{Fe}]$ and $[\mathrm{Si} / \mathrm{Fe}]$ are also rather well reproduced by all the stellar models (which actually span a wide mass interval). This is a consequence of the fact that $[\mathrm{Al} / \mathrm{Mg}]$ and $[\mathrm{Si} / \mathrm{Mg}]$ depend very weakly on the initial mass. This means that we cannot use these two ratios to discriminate the mass of the exploding star but we can only say that our pre-supernova models do reproduce them. Also $[\mathrm{Ca} / \mathrm{Fe}]$ is always within two sigma from the observed value, though the 20 and $25 \mathrm{M}_{\odot}$ models are those which provide the best fit to the data. $[\mathrm{C} / \mathrm{Fe}]$ and $[\mathrm{Na} / \mathrm{Fe}]$ are never satisfactory reproduced, the first of the two being always overestimated and the second one being systematically underestimated: the 20 and the $35 \mathrm{M}_{\odot}$ models are those for which the discrepancies are minimised. A possible way to reconcile the fit of both $[\mathrm{C} / \mathrm{Fe}]$ and $[\mathrm{Na} / \mathrm{Fe}]$ with the data could be by slightly reducing the amount of $\mathrm{C}$ left by the central He burning (e.g. by increasing the rate of the ${ }^{12} \mathrm{C}(\alpha, \gamma){ }^{16} \mathrm{O}$ reaction) since the effect of such a change goes in the right direction (see Imbriani et al. 2001). An extended set of computations would anyway be required to support such a possibility. Looking at the iron peak elements, only one of this group, i.e. Ti, is relatively well predicted by the models (the 35 and $50 \mathrm{M}_{\odot}$ models in particular): all the other elements are missed by a substantial amount by all the models in our database. Note that the discrepancies between the theoretical predictions and the data are essentially independent of the mass of the exploding star: Sc, Co, and Ni are always systematically underestimated 

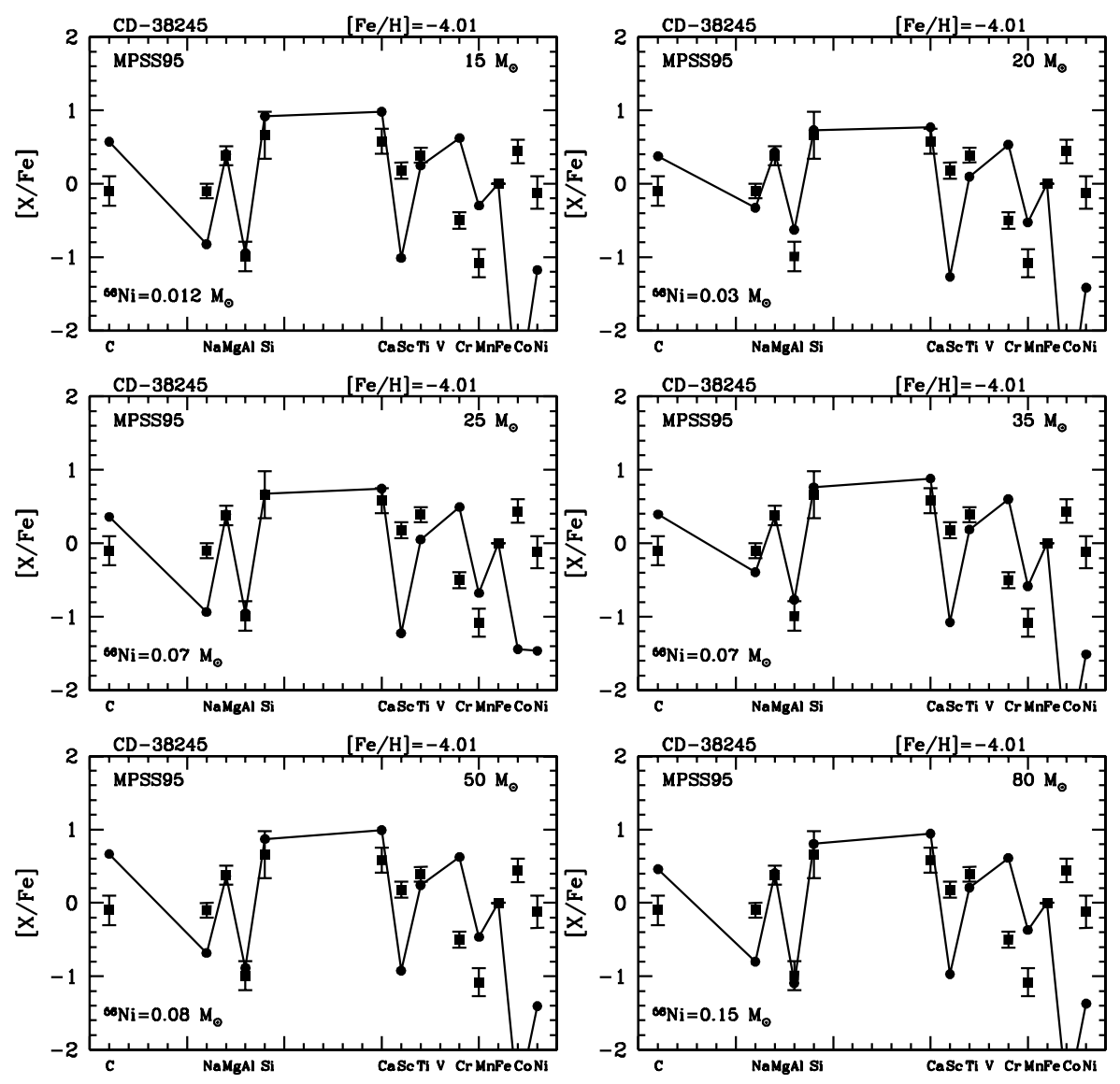

Figure 5: Fit to the CD $38^{\circ} 245$ with LC01 yields. See text for more details.

while $\mathrm{Cr}$ and $\mathrm{Mn}$ are always overestimated.

Figure 6 is similar to Figure 5 but for the WW95 yields. Since WW95 give their yields for only one value of the ${ }^{56} \mathrm{Ni}$ ejected we cannot arbitrarily change the mass cut in order to fit the observed $[\mathrm{Mg} / \mathrm{Fe}]$. However, since the abundance pattern of the elements from $\mathrm{C}$ to $\mathrm{Ca}$ does not significantly depend on the location of the mass cut, we can arbitrarily vertically shift all the theoretical predictions of these elements (open stars in Figure 6) to fit the observed $[\mathrm{Mg} / \mathrm{Fe}] \log$ ratio. By doing that we find that $[\mathrm{Al} / \mathrm{Fe}]$ is always overestimated by the models while $[\mathrm{Si} / \mathrm{Fe}]$ is always compatible with the observations except in the 30 and $35 \mathrm{M}_{\odot}$ models. This means that, at variance with our results, the relative scaling of $\mathrm{Mg}, \mathrm{Al}$, and $\mathrm{Si}$ is not independent of the initial mass, even if it does not show a continuous trend with the progenitor mass. [Ca/Fe] behaves like $[\mathrm{Si} / \mathrm{Fe}]$. The only cases in which both $[\mathrm{C} / \mathrm{Fe}]$ and $[\mathrm{Na} / \mathrm{Fe}]$ are simultaneously in agreement with the observations are 30 and $35 \mathrm{M}_{\odot}$ which are, unfortunately, the only masses that do not reproduce the observed $[\mathrm{Si} / \mathrm{Fe}]$ and $[\mathrm{Ca} / \mathrm{Fe}]$. We cannot make any comment on the comparison between the data and the theoretical yields of the iron 

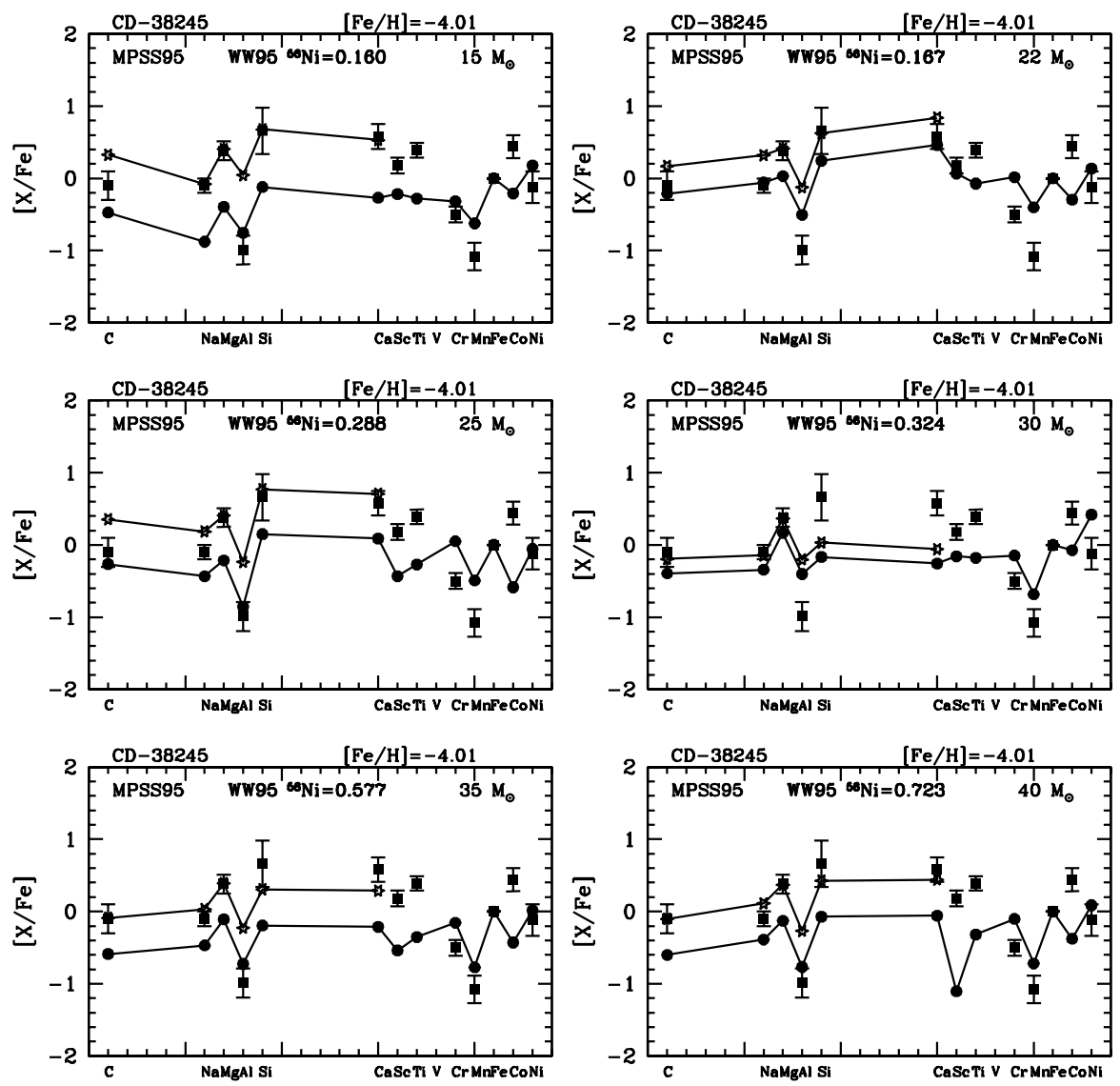

Figure 6: Fit to the CD $38^{\circ} 245$ with WW95 yields. See text for more details.

peak elements because we cannot predict how their relative scaling changes by choosing the amount of ${ }^{56} \mathrm{Ni}$ ejected needed to fit the observed $[\mathrm{Mg} / \mathrm{Fe}]$.

Figure 7 is similar to Figures 5 and 6 but for the UN02 yields. Also UN02 give their yields for just one choice of the mass cut. Also in this case we can vertically shift the abundances of all the elements from $\mathrm{C}$ to $\mathrm{Ca}$ to fit the observed $[\mathrm{Mg} / \mathrm{Fe}]$, if necessary. The only model for which we are forced to shift the theoretical yields is the $15 \mathrm{M}_{\odot}$, in all the other cases the amount of ${ }^{56} \mathrm{Ni}$ ejected is already the one able to fit the observed $[\mathrm{Mg} / \mathrm{Fe}]$. Similar to the WW95 case, the relative scaling of $\mathrm{Mg}, \mathrm{Al}$, and $\mathrm{Si}$ changes with the progenitor mass; in this case, however, there seems to be a continuous trend with the initial mass, i.e. $[\mathrm{Al} / \mathrm{Fe}]$ increases while $[\mathrm{Si} / \mathrm{Fe}]$ remains roughly constant with increasing progenitor mass (except the $15 \mathrm{M}_{\odot}$ case). The final net result is that the only models in which $[\mathrm{Mg}, \mathrm{Al}, \mathrm{Si} / \mathrm{Fe}]$ agree simultaneously with the observations are the 15 and the $20 \mathrm{M}_{\odot}$. On the contrary the only model which reproduces the observed $[\mathrm{Ca} / \mathrm{Fe}]$ is the $25 \mathrm{M}_{\odot}$. There is no model able to simultaneously fit the observed $[\mathrm{C} / \mathrm{Fe}]$ and $[\mathrm{Na} / \mathrm{Fe}]$; in particular $[\mathrm{Na} / \mathrm{Fe}]$ is always underestimated by all the models, while $[\mathrm{C} / \mathrm{Fe}]$ 

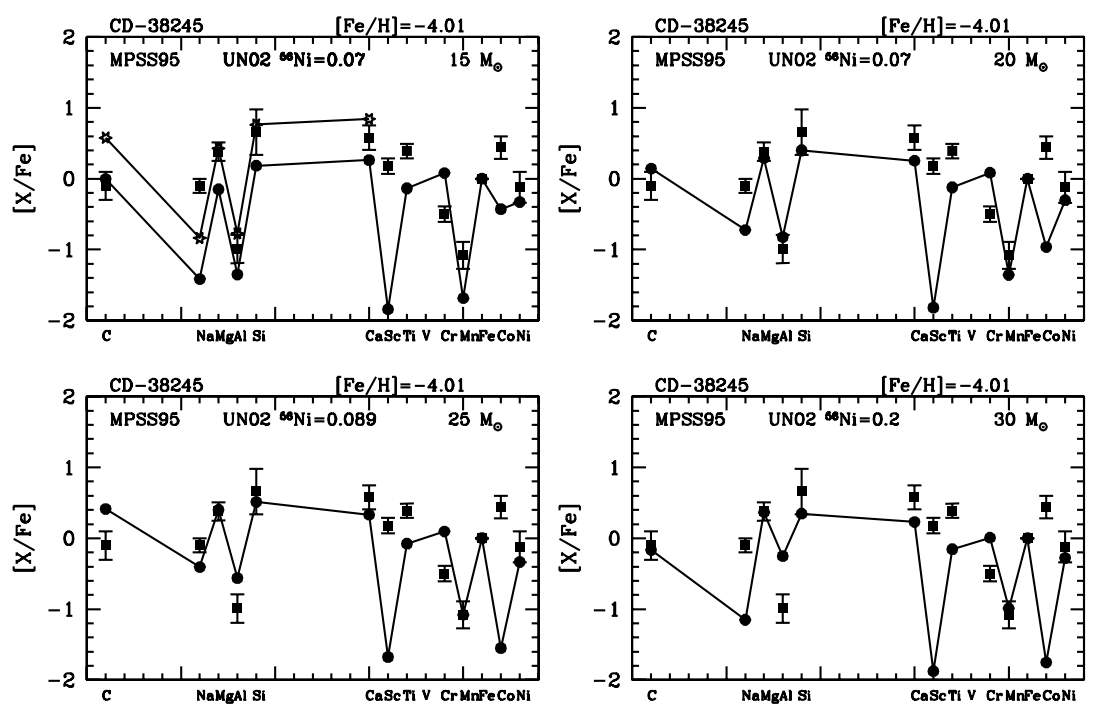

Figure 7: Fit to the CD $38^{\circ} 245$ with UN02 yields. See text for more details.

is fitted only by the 20 and $30 \mathrm{M}_{\odot}$ models. Looking at the iron peak elements, the only element abundance ratios reproduced by the UN02 models are $[\mathrm{Mn} / \mathrm{Fe}]$ and $[\mathrm{Ni} / \mathrm{Fe}]$, all the other ones being missed by a significant amount. In particular [Sc, $\mathrm{Ti}, \mathrm{Co} / \mathrm{Fe}$ ] are systematically underestimated while $[\mathrm{Cr} / \mathrm{Fe}]$ is always overestimated.

\section{Conclusions}

We have compared the three existing sets of theoretical yields produced by zero metallicity massive stars, i.e. the ones by LC01, WW95, and UN02. The results may be summarised as follows: 1) in general the yields computed by the three groups differ significantly; 2) the $[\mathrm{X} / \mathrm{Mg}](\mathrm{X}=\mathrm{C}, \mathrm{O}, \mathrm{Ne}, \mathrm{Na}, \mathrm{Al}, \mathrm{Si}, \mathrm{P}, \mathrm{S}, \mathrm{Cl}, \mathrm{Ar}, \mathrm{K}, \mathrm{Ca})$ obtained by LC01 and UN02 show a more or less continuous dependence on the progenitor mass while the ones obtained by WW95 show a much more scattered behaviour (no clear dependence on the initial mass); 3) both WW95 and UN02 predict an [O/Mg] almost flat around 0.0 dex in the mass range $13-40 \mathrm{M}_{\odot}$; however we obtain a value which increases from 0.0 dex to 0.7 dex in the mass range $15-50 \mathrm{M}_{\odot}$ : this could be a good observational check for the models; 4) within each set of yields, [Si,S,Ar, Ca/Mg] show the same dependence on the mass, i.e. their internal ratios (e.g. [Si/S], [S/Ca], [Ar/Si], and the like) are largely independent of the initial mass; 5) WW95 predict a much lower odd-even effect (especially for $\mathrm{Na}, \mathrm{Al}$, and P) than LC01 and UN02; the reason for this is difficult to understand at present; 6) the abundance pattern of most of the iron peak elements obtained by WW95, i.e. [V,Cr,Mn,Sc, Ti,Co/Fe], is compatible with our results for a proper choice of the amount of ${ }^{56} \mathrm{Ni}$ ejected, while $[\mathrm{Ni} / \mathrm{Fe}]$ is always larger than the range of values we obtain; 7) the abundance ratios of most of the iron peak elements obtained by UN02, i.e. [V,Cr, Ti, Co/Fe], are compatible with our results for a 
proper choice of the mass cut, while $[\mathrm{Sc} / \mathrm{Fe}]$ and $[\mathrm{Ni} / \mathrm{Fe}]$ always show large differences with respect to our results.

A comparison between the three sets of yields and the element abundance ratios observed in CD $38^{\circ} 245$ shows that the observations are never satisfactorily reproduced by the models. In particular, using the LC01 yields we find that: 1) the relative scaling of $\mathrm{C}$ and $\mathrm{Na}$ are never reproduced by the models; 2) [Mg,Al,Si, Ca/Fe] are always compatible with the observations regardless of the progenitor mass (except in the $50 \mathrm{M}_{\odot}$ case in which $[\mathrm{Ca} / \mathrm{Fe}]$ is overestimated by the model); 3) the iron peak elements are always missed by the models except $[\mathrm{Ti} / \mathrm{Fe}]$ which is always in very good agreement with the observations. Using the WW95 yields we find that: 1) [Mg, $\mathrm{Si}, \mathrm{Ca} / \mathrm{Fe}]$ are always compatible with the observations except for 30 and $35 \mathrm{M}_{\odot}$ which are, however, the only models which fit both $[\mathrm{C} / \mathrm{Fe}]$ and $[\mathrm{Na} / \mathrm{Fe}] ; 2)[\mathrm{Al} / \mathrm{Fe}]$ is always overestimated by the models; 3) no comment is possible for the iron peak elements because we don't know how their relative scaling changes by varying the ${ }^{56} \mathrm{Ni}$ to the value needed to fit the observed $[\mathrm{Mg} / \mathrm{Fe}]$. Using the UN02 yields we find that: 1) the abundance pattern of $[\mathrm{Mg}, \mathrm{Al}, \mathrm{Si}, \mathrm{Ca} / \mathrm{Fe}]$ is compatible with the observations for the lower mass models, i.e. 15 and $\left.20 \mathrm{M}_{\odot} ; 2\right)$ [C,Na/Fe] are never simultaneously in agreement with the observations; $3)$ the iron peak elements are missed by all the models except $[\mathrm{Mn} / \mathrm{Fe}]$ and $[\mathrm{Ni} / \mathrm{Fe}]$ that are better reproduced by the more massive stars, i.e. 25 and $30 \mathrm{M}_{\odot}$.

The final conclusion of this preliminary analysis is that at present no theoretical set of yields can satisfactory reproduce the surface chemical composition of CD $38^{\circ} 245$ under the assumption that it is formed by material enriched by the ejecta of just one zero metallicity type II supernova.

\section{Acknowledgments}

One of us (ML) thanks the scientific committee of the 2001 Conference of the Astronomical Society of Australia for having invited him to the meeting, and John Lattanzio and Brad Gibson for their very generous hospitality during his visit in Australia.

\section{References}

Auduze, J., \& Silk, J. 1995, ApJ, 451, L49

Chieffi, A., Limongi, M., Dominguez, I., \& Straniero, O. 2001a, in New Quests in Stellar Astrophysics: The Link between Stars and Cosmology (Dordrecht: Kluwer), in press

Chieffi, A., Limongi, M., Dominguez, I., \& Straniero, O. 2001b, in Chemical Enrichment of Intracluster and Intergalactic Medium, ASP Conference Series, ed. F. Matteucci, \& F. Giovannelli (San Francisco: ASP), in press

Limongi, M., Straniero, O., \& Chieffi, A. 2000, ApJS, 129, 625

Limongi, M., Chieffi, A., Straniero, O., \& Dominguez, I. 2001, in New Quests in Stellar Astrophysics: The Link between Stars and Cosmology (Dordrecht: Kluwer), in press 
Limongi, M., \& Chieffi, A. 2001, in Chemical Enrichment of Intracluster and Intergalactic Medium, ASP Conference Series, ed. F. Matteucci, \& F. Giovannelli (San Francisco: ASP), in press

McWilliam, A., Preston, G.W., Sneden, C., \& Searle, L. 1995, AJ, 109, 2757

Ryan, S.G., Norris, J.E., \& Beers T.C. 1996, ApJ, 471, 254

Umeda, H., \& Nomoto, K. 2002, ApJ, 565, 385 (UN02)

Woosley, S.E., \& Weaver, T.A. 1995, ApJS, 101, 181 (WW95) 
Table 1: Yields of the $15 \mathbf{M}_{\odot} \mathbf{Z}=\mathbf{0}$ model.

\begin{tabular}{|c|c|c|c|c|c|c|c|}
\hline $\mathrm{M}\left({ }^{56} \mathrm{Ni}\right)$ & 0.0010 & 0.0050 & 0.0100 & 0.0500 & 0.0750 & 0.1000 & 0.1160 \\
\hline $\mathrm{M}_{\text {cut }}$ & 1.81 & 1.78 & 1.77 & 1.71 & 1.68 & 1.63 & 1.60 \\
\hline $\mathrm{M}_{\text {ejected }}$ & 13.19 & 13.22 & 13.23 & 13.29 & 13.32 & 13.37 & 13.40 \\
\hline $\mathrm{H}$ & $7.73 \mathrm{E}+00$ & $7.73 \mathrm{E}+00$ & $.73 \mathrm{E}+00$ & $7.73 \mathrm{E}+00$ & $7.73 \mathrm{E}+00$ & $7.73 \mathrm{E}+00$ & $7.73 \mathrm{E}+00$ \\
\hline $\mathrm{He}$ & $4.66 \mathrm{E}+00$ & $4.66 \mathrm{E}+00$ & $4.66 \mathrm{E}+00$ & $4.66 \mathrm{E}+00$ & $4.66 \mathrm{E}+00$ & $4.66 \mathrm{E}+00$ & $4.66 \mathrm{E}+00$ \\
\hline $\mathrm{C}$ & 0E-01 & 10E-01 & 40E-01 & 40E-01 & 40E-01 & 40E-01 & $40 \mathrm{E}-01$ \\
\hline $\mathrm{N}$ & $2 \mathrm{E}-07$ & $62 \mathrm{E}-07$ & $62 \mathrm{E}-07$ & $62 \mathrm{E}-07$ & $62 \mathrm{E}-07$ & $62 \mathrm{E}-07$ & $.62 \mathrm{E}-07$ \\
\hline $\mathrm{O}$ & $16 \mathrm{E}-01$ & $3.16 \mathrm{E}-01$ & $3.16 \mathrm{E}-01$ & 16E-01 & $3.16 \mathrm{E}-01$ & 3.16E-01 & $3.16 \mathrm{E}-01$ \\
\hline $\mathrm{F}$ & 60E-11 & $4.60 \mathrm{E}-11$ & $4.60 \mathrm{E}-11$ & $4.60 \mathrm{E}-11$ & $4.60 \mathrm{E}-11$ & $4.60 \mathrm{E}-11$ & $4.60 \mathrm{E}-11$ \\
\hline $\mathrm{Ne}$ & 7.87E-03 & $7.87 \mathrm{E}-03$ & 7.87E-03 & 7.87E-03 & 7.87E-03 & 7.87E-03 & 7.87E-03 \\
\hline $\mathrm{Na}$ & 0 E- 05 & $5.10 \mathrm{E}-05$ & $5.10 \mathrm{E}-05$ & $5.10 \mathrm{E}-05$ & $5.10 \mathrm{E}-05$ & $5.10 \mathrm{E}-05$ & $5.10 \mathrm{E}-05$ \\
\hline $\mathrm{Mg}$ & $6 \mathrm{E}-02$ & $1.76 \mathrm{E}-02$ & $1.76 \mathrm{E}-02$ & $1.76 \mathrm{E}-02$ & $1.76 \mathrm{E}-02$ & $1.76 \mathrm{E}-02$ & $1.76 \mathrm{E}-02$ \\
\hline $\mathrm{Al}$ & $6 \mathrm{E}-05$ & $7.06 \mathrm{E}-05$ & $7.06 \mathrm{E}-05$ & $7.06 \mathrm{E}-05$ & 7.07E-05 & $7.07 \mathrm{E}-05$ & 7.07E-05 \\
\hline $\mathrm{Si}$ & 02 & 02 & 6.02 & 02 & 02 & -02 & $.16 \mathrm{E}-02$ \\
\hline $\mathrm{P}$ & E-05 & 05 & $0 \mathrm{E}-05$ & $72 \mathrm{E}-05$ & $.73 \mathrm{H}$ & $1.75 \mathrm{E}-05$ & $1.75 \mathrm{E}-05$ \\
\hline S & 2E-02 & OE-02 & $3.55 \mathrm{E}-02$ & 69E-02 & 3.69E-02 & $3.69 \mathrm{E}-02$ & 3.69E-02 \\
\hline $\mathrm{Cl}$ & $9 \mathrm{E}-05$ & $1.59 \mathrm{E}-05$ & $1.59 \mathrm{E}-05$ & 71E-05 & $1.97 \mathrm{E}-05$ & $3.09 \mathrm{E}-05$ & $3.16 \mathrm{E}-05$ \\
\hline $\mathrm{Ar}$ & $7 \mathrm{E}-03$ & $5.73 \mathrm{E}-03$ & $6.73 \mathrm{E}-03$ & 7.19E-03 & $7.20 \mathrm{E}-03$ & $7.20 \mathrm{E}-03$ & $7.21 \mathrm{E}-03$ \\
\hline K & $15 \mathrm{E}-06$ & $7.67 \mathrm{E}-06$ & $7.68 \mathrm{E}-06$ & 7.69E-06 & 7.70E-06 & $7.82 \mathrm{E}-06$ & 7.83E-06 \\
\hline $\mathrm{Ca}$ & $3 \mathrm{E}-03$ & $5.00 \mathrm{E}-03$ & $6.06 \mathrm{E}-03$ & $6.81 \mathrm{E}-03$ & $6.85 \mathrm{E}-03$ & $6.93 \mathrm{E}-03$ & $6.96 \mathrm{E}-03$ \\
\hline $\mathrm{Sc}$ & $3.85 \mathrm{E}-08$ & 4.06E-08 & $4.21 \mathrm{E}-08$ & $6.02 \mathrm{E}-07$ & $1.90 \mathrm{E}-06$ & $1.11 \mathrm{E}-05$ & 1.15E-05 \\
\hline $\mathrm{Ti}$ & 6.19E-06 & $2.50 \mathrm{E}-05$ & $4.41 \mathrm{E}-05$ & $8.95 \mathrm{E}-05$ & 1.37E-04 & $2.19 \mathrm{E}-04$ & $2.54 \mathrm{E}-04$ \\
\hline V & $6 \mathrm{E}-07$ & $6.38 \mathrm{E}-07$ & $8.96 \mathrm{E}-07$ & $9.72 \mathrm{E}-07$ & $9.72 \mathrm{E}-07$ & $9.73 \mathrm{E}-07$ & $9.73 \mathrm{E}-07$ \\
\hline $\mathrm{Cr}$ & $5.44 \mathrm{E}-05$ & $3.13 \mathrm{E}-04$ & $6.06 \mathrm{E}-04$ & $14 \mathrm{E}-03$ & $1.20 \mathrm{E}-03$ & $1.32 \mathrm{E}-03$ & $1.36 \mathrm{E}-03$ \\
\hline Mn & 5 E- 05 & $3.60 \mathrm{E}-05$ & $5.14 \mathrm{E}-05$ & $76 \mathrm{E}-05$ & $5.76 \mathrm{E}-05$ & $5.76 \mathrm{E}-05$ & $5.76 \mathrm{E}-05$ \\
\hline $\mathrm{Fe}$ & $5 \mathrm{E}-03$ & $5.25 \mathrm{E}-03$ & $1.03 \mathrm{E}-02$ & $08 \mathrm{E}-02$ & 7.63E-02 & $1.02 \mathrm{E}-01$ & $1.18 \mathrm{E}-01$ \\
\hline $\mathrm{Co}$ & $4.12 \mathrm{E}-08$ & $4.25 \mathrm{E}-08$ & $4.31 \mathrm{E}-08$ & $1.32 \mathrm{E}-04$ & $3.42 \mathrm{E}-04$ & $6.40 \mathrm{E}-04$ & 1.15E-03 \\
\hline $\mathrm{Ni}$ & $2.77 \mathrm{E}-05$ & $4.93 \mathrm{E}-05$ & $6.60 \mathrm{E}-05$ & $6.09 \mathrm{E}-04$ & $1.18 \mathrm{E}-03$ & $2.17 \mathrm{E}-03$ & $2.43 \mathrm{E}-03$ \\
\hline
\end{tabular}


Table 2: Yields of the $\mathbf{2 0} \mathrm{M}_{\odot} \mathrm{Z}=\mathbf{0}$ model.

\begin{tabular}{|c|c|c|c|c|c|c|c|}
\hline $\mathrm{M}\left({ }^{56} \mathrm{Ni}\right)$ & 0.0010 & 0.0100 & 0.0500 & 0.1000 & 0.1500 & 0.2000 & 0.2226 \\
\hline $\mathrm{M}_{\text {cut }}$ & 2.12 & 2.04 & 1.96 & 1.90 & 1.84 & 1.75 & 1.72 \\
\hline $\mathrm{M}_{\text {ejected }}$ & 17.88 & 17.96 & 18.04 & 18.10 & 18.16 & 18.25 & 18.28 \\
\hline $\mathrm{H}$ & $9.75 \mathrm{E}+00$ & $9.75 \mathrm{E}+0$ & $.75 \mathrm{E}+00$ & $9.75 \mathrm{E}+00$ & $9.75 \mathrm{E}+00$ & $.75 \mathrm{E}+00$ & $9.75 \mathrm{E}+00$ \\
\hline $\mathrm{He}$ & $2 \mathrm{E}+00$ & $6.22 \mathrm{E}+00$ & $22 \mathrm{E}+00$ & $6.22 \mathrm{E}+00$ & $6.22 \mathrm{E}+00$ & $22 \mathrm{E}+00$ & $6.22 \mathrm{E}+00$ \\
\hline $\mathrm{C}$ & $95 \mathrm{E}-01$ & $95 \mathrm{E}-01$ & 95E-01 & $2.95 \mathrm{E}-01$ & 95E-01 & $2.95 \mathrm{E}-01$ & $2.95 \mathrm{E}-01$ \\
\hline $\mathrm{N}$ & $25 \mathrm{E}-05$ & $2.25 \mathrm{E}-05$ & $25 \mathrm{E}-05$ & $2.25 \mathrm{E}-05$ & $.25 \mathrm{E}-05$ & $2.25 \mathrm{E}-05$ & $2.25 \mathrm{E}-05$ \\
\hline $\mathrm{O}$ & $1.07 \mathrm{E}+00$ & $1.07 \mathrm{E}+00$ & $1.07 \mathrm{E}+00$ & $1.07 \mathrm{E}+00$ & $1.07 \mathrm{E}+00$ & $1.07 \mathrm{E}+00$ & $1.07 \mathrm{E}+00$ \\
\hline $\mathrm{F}$ & 06E-08 & $1.06 \mathrm{E}-08$ & $1.06 \mathrm{E}-08$ & $1.06 \mathrm{E}-08$ & $1.06 \mathrm{E}-08$ & $1.06 \mathrm{E}-08$ & $1.06 \mathrm{E}-08$ \\
\hline $\mathrm{Ne}$ & 52E-02 & 2.62E-02 & $2.62 \mathrm{E}-02$ & 2.62E-02 & 2.62E-02 & $2.62 \mathrm{E}-02$ & $2.62 \mathrm{E}-02$ \\
\hline $\mathrm{Na}$ & $3 \mathrm{E}-04$ & $1.53 \mathrm{E}-04$ & $1.53 \mathrm{E}-04$ & $1.53 \mathrm{E}-04$ & $1.53 \mathrm{E}-04$ & $1.53 \mathrm{E}-04$ & $1.53 \mathrm{E}-04$ \\
\hline $\mathrm{Mg}$ & 70E-02 & $4.70 \mathrm{E}-02$ & $4.70 \mathrm{E}-02$ & 4.70E-02 & 4.70E-02 & $4.70 \mathrm{E}-02$ & 4.70E-02 \\
\hline $\mathrm{Al}$ & $6 \mathrm{E}-04$ & $2.56 \mathrm{E}-04$ & $2.56 \mathrm{E}-04$ & $2.56 \mathrm{E}-04$ & $2.57 \mathrm{E}-04$ & $2.57 \mathrm{E}-04$ & $2.57 \mathrm{E}-04$ \\
\hline $\mathrm{Si}$ & E-02 & 01 & 1 & -01 & 46E-01 & -01 & $46 \mathrm{E}-01$ \\
\hline $\mathrm{P}$ & E-05 & $3 \mathrm{E}-05$ & 901 & 0E-05 & 91E-05 & $7.93 \mathrm{E}-05$ & 7.93E-05 \\
\hline S & -02 & $0 \mathrm{E}-02$ & 8.65 & $65 \mathrm{E}-02$ & $65 \mathrm{E}-02$ & $8.65 \mathrm{E}-02$ & $8.65 \mathrm{E}-02$ \\
\hline $\mathrm{Cl}$ & $8 \mathrm{E}-05$ & $4.70 \mathrm{E}-05$ & $4.70 \mathrm{l}$ & 4.73E-05 & 4.87E-05 & $6.50 \mathrm{E}-05$ & $6.85 \mathrm{E}-05$ \\
\hline $\mathrm{Ar}$ & $0 \mathrm{E}-03$ & $1.32 \mathrm{E}-02$ & $1.66 \mathrm{E}-02$ & 66E-02 & $1.66 \mathrm{E}-02$ & $1.66 \mathrm{E}-02$ & $1.66 \mathrm{E}-02$ \\
\hline K & $7 \mathrm{E}-05$ & $1.97 \mathrm{E}-05$ & $1.98 \mathrm{E}-05$ & $1.98 \mathrm{E}-05$ & $1.98 \mathrm{E}-05$ & $2.00 \mathrm{E}-05$ & $2.00 \mathrm{E}-05$ \\
\hline $\mathrm{Ca}$ & 99E-03 & $1.13 \mathrm{E}-02$ & $1.53 \mathrm{E}-02$ & $54 \mathrm{E}-02$ & $1.54 \mathrm{E}-02$ & $1.55 \mathrm{E}-02$ & $1.56 \mathrm{E}-02$ \\
\hline $\mathrm{Sc}$ & 34E-08 & $9.40 \mathrm{E}-08$ & $9.98 \mathrm{E}-08$ & $2.20 \mathrm{E}-07$ & 8.64E-07 & $1.59 \mathrm{E}-05$ & $1.84 \mathrm{E}-05$ \\
\hline $\mathrm{Ti}$ & $93 \mathrm{E}-06$ & $55 \mathrm{E}-05$ & $1.47 \mathrm{E}-04$ & $1.77 \mathrm{E}-04$ & $2.45 \mathrm{E}-04$ & $3.68 \mathrm{E}-04$ & $4.05 \mathrm{E}-04$ \\
\hline V & $1 \mathrm{E}-07$ & 67E-06 & $3.10 \mathrm{E}-06$ & $3.10 \mathrm{E}-06$ & $3.10 \mathrm{E}-06$ & $3.10 \mathrm{E}-06$ & $3.10 \mathrm{E}-06$ \\
\hline $\mathrm{Cr}$ & $15 \mathrm{E}-05$ & $6.72 \mathrm{E}-04$ & $2.42 \mathrm{E}-03$ & $2.46 \mathrm{E}-03$ & $2.56 \mathrm{E}-03$ & $2.73 \mathrm{E}-03$ & $2.78 \mathrm{E}-03$ \\
\hline Mn & $2 \mathrm{E}-05$ & $8.34 \mathrm{E}-05$ & $1.83 \mathrm{E}-04$ & $1.83 \mathrm{E}-04$ & $1.83 \mathrm{E}-04$ & $1.83 \mathrm{E}-04$ & $1.83 \mathrm{E}-04$ \\
\hline $\mathrm{Fe}$ & E-03 & $.06 \mathrm{E}-02$ & - & $1.02 \mathrm{E}-01$ & $.53 \mathrm{E}-01$ & $2.04 \mathrm{E}-01$ & $2.27 \mathrm{E}-01$ \\
\hline $\mathrm{Cc}$ & E-08 & $99 \mathrm{E}-08$ & 9.111 & $1.81 \mathrm{E}-04$ & $5.21 \mathrm{E}-04$ & $8.44 \mathrm{E}-04$ & $9.98 \mathrm{E}-04$ \\
\hline $\mathrm{Ni}$ & $3.95 \mathrm{E}-05$ & 8.03E-05 & $1.52 \mathrm{E}-04$ & $6.88 \mathrm{E}-04$ & $1.43 \mathrm{E}-03$ & $3.22 \mathrm{E}-03$ & $3.94 \mathrm{E}-03$ \\
\hline
\end{tabular}


Table 3: Yields of the $\mathbf{2 5} \mathbf{M}_{\odot} \mathbf{Z}=\mathbf{0}$ model.

\begin{tabular}{|c|c|c|c|c|c|c|c|}
\hline $\mathrm{M}\left({ }^{56} \mathrm{Ni}\right)$ & 0.0010 & 0.0100 & 0.0500 & 0.1000 & 0.1500 & 0.2000 & 0.3288 \\
\hline $\mathrm{M}_{\text {cut }}$ & 2.50 & 2.40 & 2.30 & 2.24 & 2.18 & 2.12 & 1.93 \\
\hline $\mathrm{M}_{\text {ejected }}$ & 22.50 & 22.60 & 22.70 & 22.76 & 22.82 & 22.88 & 23.07 \\
\hline $\mathrm{H}$ & $1.14 \mathrm{E}+01$ & $1.14 \mathrm{E}+01$ & $1.14 \mathrm{E}+01$ & $.14 \mathrm{E}+01$ & $1.14 \mathrm{E}+01$ & $.14 \mathrm{E}+01$ & $1.14 \mathrm{E}+01$ \\
\hline $\mathrm{He}$ & $7.85 \mathrm{E}+00$ & $7.85 \mathrm{E}+00$ & $.85 \mathrm{E}+00$ & $7.85 \mathrm{E}+00$ & $7.85 \mathrm{E}+00$ & $7.85 \mathrm{E}+00$ & $7.85 \mathrm{E}+00$ \\
\hline $\mathrm{C}$ & $3 \mathrm{E}-01$ & $3 \mathrm{E}-01$ & 13E-01 & $4.13 \mathrm{E}-01$ & 13E-01 & $4.13 \mathrm{E}-01$ & $.13 \mathrm{E}-01$ \\
\hline $\mathrm{N}$ & $54 \mathrm{E}-02$ & $54 \mathrm{E}-02$ & $54 \mathrm{E}-02$ & $6.54 \mathrm{E}-02$ & $54 \mathrm{E}-02$ & $.54 \mathrm{E}-02$ & $6.54 \mathrm{E}-02$ \\
\hline $\mathrm{O}$ & $2.05 \mathrm{E}+00$ & $2.05 \mathrm{E}+00$ & $2.05 \mathrm{E}+00$ & $2.05 \mathrm{E}+00$ & $2.05 \mathrm{E}+00$ & $2.05 \mathrm{E}+00$ & $2.05 \mathrm{E}+00$ \\
\hline $\mathrm{F}$ & 73E-08 & $8.73 \mathrm{E}-08$ & $8.73 \mathrm{E}-08$ & $8.73 \mathrm{E}-08$ & 8.73E-08 & $8.73 \mathrm{E}-08$ & 8.73E-08 \\
\hline $\mathrm{Ne}$ & $27 \mathrm{E}-02$ & $4.27 \mathrm{E}-02$ & $4.27 \mathrm{E}-02$ & $4.27 \mathrm{E}-02$ & $4.27 \mathrm{E}-02$ & $4.27 \mathrm{E}-02$ & $4.27 \mathrm{E}-02$ \\
\hline $\mathrm{Na}$ & $34 \mathrm{E}-04$ & $2.34 \mathrm{E}-04$ & $2.34 \mathrm{~F}$ & $2.34 \mathrm{E}-04$ & $2.34 \mathrm{E}-04$ & $2.34 \mathrm{E}-04$ & $2.34 \mathrm{E}-04$ \\
\hline $\mathrm{Mg}$ & $78 \mathrm{E}-02$ & $6.78 \mathrm{E}-02$ & $6.78 \mathrm{I}$ & $6.78 \mathrm{E}-02$ & $6.78 \mathrm{E}-02$ & $6.78 \mathrm{E}-02$ & $6.78 \mathrm{E}-02$ \\
\hline $\mathrm{Al}$ & 39E-04 & $3.39 \mathrm{E}-04$ & 3391 & $3.39 \mathrm{E}-04$ & $3.39 \mathrm{E}-04$ & $3.39 \mathrm{E}-04$ & $3.39 \mathrm{E}-04$ \\
\hline $\mathrm{Si}$ & 3E-01 & $1.69 \mathrm{E}-01$ & & E-01 & -01 & $1.96 \mathrm{E}-01$ & $.96 \mathrm{E}-01$ \\
\hline $\mathrm{P}$ & -05 & 05 & 7 & E-05 & -05 & IE-05 & $.34 \mathrm{E}-05$ \\
\hline S & 02 & 02 & 1 & $1.17 \mathrm{E}-01$ & 17E-01 & $1.17 \mathrm{E}-01$ & $1.17 \mathrm{E}-01$ \\
\hline $\mathrm{Cl}$ & E-05 & $4.80 \mathrm{E}-05$ & 4.8 & $4.84 \mathrm{E}-05$ & $.98 \mathrm{E}-05$ & $5.13 \mathrm{E}-05$ & $7.75 \mathrm{E}-05$ \\
\hline $\operatorname{Ar}$ & 4E-02 & $74 \mathrm{E}-02$ & 02 & $2.27 \mathrm{E}-02$ & $.27 \mathrm{E}-02$ & $2.27 \mathrm{E}-02$ & $2.27 \mathrm{E}-02$ \\
\hline K & $5 \mathrm{E}-05$ & $95 \mathrm{E}-05$ & $1.96 \mathrm{E}-05$ & $1.96 \mathrm{E}-05$ & $1.96 \mathrm{E}-05$ & $1.96 \mathrm{E}-05$ & $1.99 \mathrm{E}-05$ \\
\hline $\mathrm{Ca}$ & $.82 \mathrm{E}-03$ & 51E-02 & $2.07 \mathrm{I}$ & $2.12 \mathrm{E}-02$ & $2.12 \mathrm{E}-02$ & $2.13 \mathrm{E}-02$ & $2.15 \mathrm{E}-02$ \\
\hline $\mathrm{Sc}$ & $.23 \mathrm{E}-07$ & $1.30 \mathrm{E}-07$ & $1.37 \mathrm{E}-07$ & $2.55 \mathrm{E}-07$ & $9.48 \mathrm{E}-07$ & $1.63 \mathrm{E}-06$ & $2.75 \mathrm{E}-05$ \\
\hline $\mathrm{Ti}$ & 77E-05 & $5.99 \mathrm{E}-05$ & $1.77 \mathrm{I}$ & $2.05 \mathrm{E}-04$ & $2.50 \mathrm{E}-04$ & $3.06 \mathrm{E}-04$ & $5.23 \mathrm{E}-04$ \\
\hline V & $3.08 \mathrm{E}-07$ & $1.41 \mathrm{E}-06$ & $2.66 \mathrm{E}-06$ & $2.72 \mathrm{E}-06$ & $2.72 \mathrm{E}-06$ & $2.72 \mathrm{E}-06$ & 2.72E-06 \\
\hline $\mathrm{Cr}$ & $5.89 \mathrm{E}-05$ & $6.73 \mathrm{E}-04$ & $2.73 \mathrm{E}-03$ & 3.31E-03 & $3.37 \mathrm{E}-03$ & $3.45 \mathrm{E}-03$ & $3.75 \mathrm{E}-03$ \\
\hline Mn & $1.78 \mathrm{E}-05$ & $7.24 \mathrm{E}-05$ & $1.48 \mathrm{E}-04$ & E-04 & $.55 \mathrm{E}-04$ & $1.55 \mathrm{E}-04$ & $1.55 \mathrm{E}-04$ \\
\hline $\mathrm{Fe}$ & $24 \mathrm{E}-03$ & $1.05 \mathrm{E}-02$ & $5.08 \mathrm{E}$ & $1.01 \mathrm{E}-01$ & $1.52 \mathrm{E}-01$ & $2.03 \mathrm{E}-01$ & $3.33 \mathrm{E}-01$ \\
\hline $\mathrm{Cc}$ & OE- -07 & $1.22 \mathrm{E}-07$ & 1.24 & $4.18 \mathrm{E}-05$ & 1.39E-04 & 3.33E-04 & 8.31E-04 \\
\hline $\mathrm{Ni}$ & $4.37 \mathrm{E}-05$ & $8.22 \mathrm{E}-05$ & $1.40 \mathrm{E}-04$ & $6.21 \mathrm{E}-04$ & $1.56 \mathrm{E}-03$ & $2.41 \mathrm{E}-03$ & $6.56 \mathrm{E}-03$ \\
\hline
\end{tabular}


Table 4: Yields of the $\mathbf{3 5} \mathbf{M}_{\odot} \mathbf{Z}=\mathbf{0}$ model.

\begin{tabular}{|c|c|c|c|c|c|c|c|}
\hline $\mathrm{M}\left({ }^{56} \mathrm{Ni}\right)$ & 0.0010 & 0.0100 & 0.0500 & 0.1000 & 0.1500 & 0.2000 & 0.6422 \\
\hline $\mathrm{M}_{\text {cut }}$ & 2.96 & 2.84 & 2.67 & 2.60 & 2.54 & 2.49 & 1.93 \\
\hline $\mathrm{M}_{\text {ejected }}$ & 32.04 & 32.16 & 32.33 & 32.40 & 32.46 & 32.51 & 33.07 \\
\hline $\mathrm{H}$ & $1.47 \mathrm{E}+01$ & $1.47 \mathrm{E}+01$ & $1.47 \mathrm{E}+01$ & $1.47 \mathrm{E}+01$ & $1.47 \mathrm{E}+01$ & $47 \mathrm{E}+01$ & $.47 \mathrm{E}+01$ \\
\hline $\mathrm{He}$ & $1.06 \mathrm{E}+01$ & $1.06 \mathrm{E}+01$ & $.06 \mathrm{E}+01$ & $1.06 \mathrm{E}+01$ & $1.06 \mathrm{E}+01$ & $1.06 \mathrm{E}+01$ & $1.06 \mathrm{E}+01$ \\
\hline $\mathrm{C}$ & 08E-01 & $8 \mathrm{E}-01$ & 08E-01 & 08E-01 & 08E-01 & $08 \mathrm{E}-01$ & $5.08 \mathrm{E}-01$ \\
\hline $\mathrm{N}$ & $2 \mathrm{E}-04$ & 82E-04 & $82 \mathrm{E}-04$ & $3.82 \mathrm{E}-04$ & 82E-04 & $3.82 \mathrm{E}-04$ & $3.82 \mathrm{E}-04$ \\
\hline $\mathrm{O}$ & $4.93 \mathrm{E}+00$ & $4.93 \mathrm{E}+00$ & $4.93 \mathrm{E}+00$ & $4.93 \mathrm{E}+00$ & $4.93 \mathrm{E}+00$ & $4.93 \mathrm{E}+00$ & $4.93 \mathrm{E}+00$ \\
\hline $\mathrm{F}$ & 3.63E-07 & $3.63 \mathrm{E}-07$ & $3.63 \mathrm{E}-07$ & $3.63 \mathrm{E}-07$ & 3.63E-07 & $3.63 \mathrm{E}-07$ & 3.63E-07 \\
\hline $\mathrm{Ne}$ & $3.33 \mathrm{E}-01$ & 3.33E-01 & $3.33 \mathrm{E}-01$ & $3.33 \mathrm{E}-01$ & $.33 \mathrm{E}-01$ & $3.33 \mathrm{E}-01$ & $3.33 \mathrm{E}-01$ \\
\hline $\mathrm{Na}$ & $55 \mathrm{E}-04$ & $8.55 \mathrm{E}-04$ & $8.55 \mathrm{E}-04$ & $8.55 \mathrm{E}-04$ & $.55 \mathrm{E}-04$ & $8.55 \mathrm{E}-04$ & $8.55 \mathrm{E}-04$ \\
\hline $\mathrm{Mg}$ & $2 \mathrm{E}-01$ & $1.02 \mathrm{E}-01$ & $1.02 \mathrm{E}-01$ & $1.02 \mathrm{E}-01$ & 1.02E-01 & $1.02 \mathrm{E}-01$ & $.02 \mathrm{E}-01$ \\
\hline $\mathrm{Al}$ & $4 \mathrm{E}-04$ & $5.94 \mathrm{E}-04$ & $594 \mathrm{~F}$ & $5.94 \mathrm{E}-04$ & $5.94 \mathrm{E}-04$ & E-04 & $.94 \mathrm{E}-04$ \\
\hline $\mathrm{Si}$ & 1E-01 & & 2.5 & -01 & -01 & -01 & $2.66 \mathrm{E}-01$ \\
\hline $\mathrm{P}$ & 5 & 05 & 5 & 05 & 05 & -05 & $6.09 \mathrm{E}-05$ \\
\hline S & 02 & 01 & 1 & -01 & 68E-01 & $1.68 \mathrm{E}-01$ & $1.68 \mathrm{E}-01$ \\
\hline $\mathrm{Cl}$ & $4 \mathrm{E}-05$ & $4.36 \mathrm{E}-05$ & 4.3 & $4.38 \mathrm{E}-05$ & 41E-05 & $4.46 \mathrm{E}-05$ & $6.66 \mathrm{E}-05$ \\
\hline $\operatorname{Ar}$ & 3E-02 & $2.20 \mathrm{E}-02$ & 14E-02 & $34 \mathrm{E}-02$ & $35 \mathrm{E}-02$ & $3.35 \mathrm{E}-02$ & $3.36 \mathrm{E}-02$ \\
\hline K & $3 \mathrm{E}-05$ & $1.94 \mathrm{E}-05$ & $1.95 \mathrm{E}-05$ & $1.95 \mathrm{E}-05$ & $1.95 \mathrm{E}-05$ & $1.95 \mathrm{E}-05$ & $1.99 \mathrm{E}-05$ \\
\hline $\mathrm{Ca}$ & $28 \mathrm{E}-02$ & $1.99 \mathrm{E}-02$ & $2.92 \mathrm{E}-02$ & 22E-02 & $3.24 \mathrm{E}-02$ & $3.24 \mathrm{E}-02$ & $3.28 \mathrm{E}-02$ \\
\hline $\mathrm{Sc}$ & $69 \mathrm{E}-07$ & $1.78 \mathrm{E}-07$ & $1.88 \mathrm{E}-07$ & $1.92 \mathrm{E}-07$ & $2.92 \mathrm{E}-07$ & $5.37 \mathrm{E}-07$ & $2.41 \mathrm{E}-05$ \\
\hline $\mathrm{Ti}$ & 19E-05 & $6.37 \mathrm{E}-05$ & $2.20 \mathrm{E}-04$ & $3.17 \mathrm{E}-04$ & 3.33E-04 & $3.62 \mathrm{E}-04$ & 7.99E-04 \\
\hline V & 77E-07 & $1.26 \mathrm{E}-06$ & $3.17 \mathrm{E}-06$ & $3.83 \mathrm{E}-06$ & $3.89 \mathrm{E}-06$ & $3.89 \mathrm{E}-06$ & 3.89E-06 \\
\hline $\mathrm{Cr}$ & $5.65 \mathrm{E}-05$ & $6.58 \mathrm{E}-04$ & $3.07 \mathrm{E}-03$ & $5.18 \mathrm{E}-03$ & $5.41 \mathrm{E}-03$ & $5.45 \mathrm{E}-03$ & $6.05 \mathrm{E}-03$ \\
\hline Mn & $1.76 \mathrm{E}-05$ & $6.81 \mathrm{E}-05$ & $1.73 \mathrm{E}-04$ & $2.28 \mathrm{E}-04$ & $2.34 \mathrm{E}-04$ & $2.34 \mathrm{E}-04$ & $2.34 \mathrm{E}-04$ \\
\hline $\mathrm{Fe}$ & $1.23 \mathrm{E}-03$ & $1.05 \mathrm{E}-02$ & $5.09 \mathrm{E}-02$ & $1.01 \mathrm{E}-01$ & $1.52 \mathrm{E}-01$ & $2.02 \mathrm{E}-01$ & $6.56 \mathrm{E}-01$ \\
\hline $\mathrm{Cc}$ & 07 & 2.17E-07 & $2.19 \mathrm{E}-07$ & $2.20 \mathrm{E}-07$ & $5.72 \mathrm{E}-05$ & $1.29 \mathrm{E}-04$ & $3.22 \mathrm{E}-03$ \\
\hline $\mathrm{Ni}$ & $5.84 \mathrm{E}-05$ & $9.84 \mathrm{E}-05$ & $1.67 \mathrm{E}-04$ & $2.09 \mathrm{E}-04$ & $8.29 \mathrm{E}-04$ & $1.59 \mathrm{E}-03$ & 7.16E-03 \\
\hline
\end{tabular}


Table 5: Yields of the $50 \mathbf{M}_{\odot} \mathbf{Z}=\mathbf{0}$ model.

\begin{tabular}{|c|c|c|c|c|c|c|c|}
\hline $\mathrm{M}\left({ }^{56} \mathrm{Ni}\right)$ & 0.0010 & 0.0100 & 0.0500 & 0.1000 & 0.1500 & 0.2000 & 1.0198 \\
\hline $\mathrm{M}_{\text {cut }}$ & 3.83 & 3.68 & 3.41 & 3.29 & 3.23 & 3.17 & 2.18 \\
\hline $\mathrm{M}_{\text {ejected }}$ & 46.17 & 46.32 & 46.59 & 46.71 & 46.77 & 46.83 & 47.82 \\
\hline $\mathrm{H}$ & $1.94 \mathrm{E}+01$ & $1.94 \mathrm{E}+0$ & $.94 \mathrm{E}+01$ & $1.94 \mathrm{E}+0$ & $1.94 \mathrm{E}+01$ & $1.94 \mathrm{E}+01$ & $1.94 \mathrm{E}+01$ \\
\hline $\mathrm{He}$ & $1 \mathrm{E}+01$ & $1.51 \mathrm{E}+01$ & $51 \mathrm{E}+01$ & $51 \mathrm{E}+01$ & $51 \mathrm{E}+01$ & $51 \mathrm{E}+01$ & $.51 \mathrm{E}+01$ \\
\hline $\mathrm{C}$ & $8 \mathrm{E}+00$ & $1.08 \mathrm{E}+00$ & $08 \mathrm{E}+00$ & $08 \mathrm{E}+00$ & $1.08 \mathrm{E}+00$ & $08 \mathrm{E}+00$ & $.08 \mathrm{E}+00$ \\
\hline $\mathrm{N}$ & $4 \mathrm{E}-07$ & $14 \mathrm{E}-07$ & $14 \mathrm{E}-07$ & $14 \mathrm{E}-07$ & $14 \mathrm{E}-07$ & $.14 \mathrm{E}-07$ & $3.14 \mathrm{E}-07$ \\
\hline $\mathrm{O}$ & $8.97 \mathrm{E}+00$ & $8.97 \mathrm{E}+00$ & $8.97 \mathrm{E}+00$ & $8.97 \mathrm{E}+00$ & $8.97 \mathrm{E}+00$ & $8.97 \mathrm{E}+00$ & $8.97 \mathrm{E}+00$ \\
\hline $\mathrm{F}$ & 47E-09 & 2.47E-09 & $2.47 \mathrm{E}-09$ & $2.47 \mathrm{E}-09$ & 2.47E-09 & $2.47 \mathrm{E}-09$ & 2.47E-09 \\
\hline $\mathrm{Ne}$ & $4 \mathrm{E}-01$ & $3.24 \mathrm{E}-01$ & $3.24 \mathrm{E}-01$ & $3.24 \mathrm{E}-01$ & $3.24 \mathrm{E}-01$ & $3.24 \mathrm{E}-01$ & $3.24 \mathrm{E}-01$ \\
\hline $\mathrm{Na}$ & $2 \mathrm{E}-04$ & $42 \mathrm{E}-04$ & $5.42 \mathrm{E}-04$ & $.42 \mathrm{E}-04$ & $42 \mathrm{E}-04$ & $.42 \mathrm{E}-04$ & $5.42 \mathrm{E}-04$ \\
\hline $\mathrm{Mg}$ & $1 \mathrm{E}-01$ & 31E-01 & $1.31 \mathrm{E}-01$ & 31E-01 & 1.31E-01 & $1.31 \mathrm{E}-01$ & $.31 \mathrm{E}-01$ \\
\hline $\mathrm{Al}$ & $1 \mathrm{E}-04$ & 41E-04 & $5.41 \mathrm{E}-04$ & $11 \mathrm{E}-04$ & $41 \mathrm{E}-04$ & 41E-04 & $5.41 \mathrm{E}-04$ \\
\hline $\mathrm{Si}$ & & & 01 & 01 & -01 & -01 & 4.30E-01 \\
\hline $\mathrm{P}$ & & 05 & 5 & 05 & 00E-04 & $1.00 \mathrm{E}-04$ & $1.01 \mathrm{E}-04$ \\
\hline S & 1 & 1 & 01 & 01 & $.78 \mathrm{E}-01$ & $2.78 \mathrm{E}-01$ & $2.78 \mathrm{E}-01$ \\
\hline $\mathrm{Cl}$ & 05 & $39 \mathrm{E}-05$ & $7.42 \mathrm{E}$ & 43E-05 & $44 \mathrm{E}-05$ & $.44 \mathrm{E}-05$ & $1.13 \mathrm{E}-04$ \\
\hline $\mathrm{Ar}$ & E-02 & $9 \mathrm{E}-02$ & $4.76 \mathrm{E}-02$ & 34E-02 & $46 \mathrm{E}-02$ & 49E-02 & $5.50 \mathrm{E}-02$ \\
\hline K & $30 \mathrm{E}-05$ & 31E-05 & $3.32 \mathrm{E}-05$ & $3.33 \mathrm{E}-05$ & $3.33 \mathrm{E}-05$ & $3.33 \mathrm{E}-05$ & $3.41 \mathrm{E}-05$ \\
\hline $\mathrm{Ca}$ & $92 \mathrm{E}-02$ & $92 \mathrm{E}-02$ & $4.34 \mathrm{E}-02$ & $5.01 \mathrm{E}-02$ & $.22 \mathrm{E}-02$ & $5.28 \mathrm{E}-02$ & $5.34 \mathrm{E}-02$ \\
\hline $\mathrm{Sc}$ & $93 \mathrm{E}-07$ & 08E-07 & $3.21 \mathrm{E}-07$ & $3.28 \mathrm{E}-07$ & 3.31E-07 & 3.33E-07 & $5.08 \mathrm{E}-05$ \\
\hline $\mathrm{Ti}$ & 40E-05 & 89E-05 & $2.63 \mathrm{E}-04$ & $4.09 \mathrm{E}-04$ & $.88 \mathrm{E}-04$ & $5.20 \mathrm{E}-04$ & $1.20 \mathrm{E}-03$ \\
\hline V & $3 \mathrm{E}-07$ & $1.27 \mathrm{E}-06$ & $4.41 \mathrm{E}-06$ & $6.13 \mathrm{E}-06$ & $6.91 \mathrm{E}-06$ & $7.30 \mathrm{E}-06$ & 7.30E-06 \\
\hline $\mathrm{Cr}$ & $5.55 \mathrm{E}-05$ & $6.31 \mathrm{E}-04$ & $3.32 \mathrm{E}-03$ & $5.92 \mathrm{E}-03$ & $7.85 \mathrm{E}-03$ & 8.93E-03 & $9.88 \mathrm{E}-03$ \\
\hline Mn & 05 & $7.20 \mathrm{E}-05$ & $2.32 \mathrm{E}-04$ & $3.43 \mathrm{E}-04$ & $17 \mathrm{E}-04$ & $4.70 \mathrm{E}-04$ & $4.70 \mathrm{E}-04$ \\
\hline $\mathrm{Fe}$ & & $5 \mathrm{E}$ & $5.12 \mathrm{E}-02$ & $1.02 \mathrm{E}$ & $52 \mathrm{E}-01$ & $2.02 \mathrm{E}-01$ & $1.04 \mathrm{E}+00$ \\
\hline $\mathrm{Cc}$ & & $4.50 \mathrm{~L}-01$ & $4.54 \mathrm{E}-07$ & & $4.56 \mathrm{E}-07$ & $1.09 \mathrm{E}-05$ & $3.90 \mathrm{E}-03$ \\
\hline $\mathrm{Ni}$ & $9.37 \mathrm{E}-05$ & $1.39 \mathrm{E}-04$ & $2.36 \mathrm{E}-04$ & 2.93E-04 & $3.34 \mathrm{E}-04$ & $4.42 \mathrm{E}-04$ & $1.05 \mathrm{E}-02$ \\
\hline
\end{tabular}


Table 6: Yields of the $80 \mathbf{M}_{\odot} \mathbf{Z}=\mathbf{0}$ model.

\begin{tabular}{|c|c|c|c|c|c|c|c|}
\hline $\mathrm{M}\left({ }^{56} \mathrm{Ni}\right)$ & 0.0010 & 0.0100 & 0.0500 & 0.1000 & 0.1500 & 0.2000 & 2.1325 \\
\hline $\mathrm{M}_{\text {cut }}$ & 5.99 & 5.71 & 5.30 & 5.01 & 4.85 & 4.75 & 2.39 \\
\hline $\mathrm{M}_{\text {ejected }}$ & 74.01 & 74.29 & 74.70 & 74.99 & 75.15 & 75.25 & 77.61 \\
\hline $\mathrm{H}$ & $2.67 \mathrm{E}+01$ & $.67 \mathrm{E}+0$ & $67 \mathrm{E}+01$ & $2.67 \mathrm{E}+\mathrm{c}$ & $2.67 \mathrm{E}+\mathrm{c}$ & $67 \mathrm{E}+01$ & $2.67 \mathrm{E}+01$ \\
\hline $\mathrm{He}$ & $15 \mathrm{E}+01$ & $45 \mathrm{E}+01$ & $45 \mathrm{E}+01$ & $45 \mathrm{E}+01$ & $2.45 \mathrm{E}+01$ & $45 \mathrm{E}+01$ & $.45 \mathrm{E}+01$ \\
\hline $\mathrm{C}$ & $1 \mathrm{E}+00$ & $1.41 \mathrm{E}+00$ & $41 \mathrm{E}+00$ & $41 \mathrm{E}+00$ & $1.41 \mathrm{E}+00$ & $41 \mathrm{E}+00$ & $1.41 \mathrm{E}+00$ \\
\hline $\mathrm{N}$ & 3E-07 & $63 \mathrm{E}-07$ & 63E-07 & 63E-07 & 63E-07 & $9.63 \mathrm{E}-07$ & $.63 \mathrm{E}-07$ \\
\hline $\mathrm{O}$ & $30 \mathrm{E}+01$ & $1.80 \mathrm{E}+01$ & $.80 \mathrm{E}+01$ & $1.80 \mathrm{E}+01$ & $1.80 \mathrm{E}+01$ & $1.80 \mathrm{E}+01$ & $1.80 \mathrm{E}+01$ \\
\hline $\mathrm{F}$ & 84E-09 & 2.84E-09 & $2.84 \mathrm{E}-09$ & $2.84 \mathrm{E}-09$ & 2.84E-09 & $2.84 \mathrm{E}-09$ & 2.84E-09 \\
\hline $\mathrm{Ne}$ & $1.08 \mathrm{E}+00$ & $1.08 \mathrm{E}+00$ & $1.08 \mathrm{E}+00$ & $1.08 \mathrm{E}+00$ & $1.08 \mathrm{E}+00$ & $1.08 \mathrm{E}+00$ & $1.08 \mathrm{E}+00$ \\
\hline $\mathrm{Na}$ & 31E-04 & $8.31 \mathrm{E}-04$ & $8.31 \mathrm{E}-04$ & $8.31 \mathrm{E}-04$ & 8.31E-04 & $8.31 \mathrm{E}-04$ & 8.31E-04 \\
\hline $\mathrm{Mg}$ & $3 \mathrm{E}-01$ & $23 \mathrm{E}-01$ & $.23 \mathrm{E}-01$ & $23 \mathrm{E}-01$ & $23 \mathrm{E}-01$ & $.23 \mathrm{E}-01$ & $23 \mathrm{E}-01$ \\
\hline $\mathrm{Al}$ & & $14 \mathrm{E}-04$ & & E-04 & $44 \mathrm{E}-04$ & E-04 & 45E-04 \\
\hline $\mathrm{Si}$ & & 01 & & & 01 & -01 & -01 \\
\hline $\mathrm{P}$ & & 04 & 3.0 & 04 & 04 & $3.05 \mathrm{E}-04$ & $.08 \mathrm{E}-04$ \\
\hline S & $42 \mathrm{E}-01$ & 01 & 4.70 & 01 & $.92 \mathrm{E}-01$ & $6.11 \mathrm{E}-01$ & $35 \mathrm{E}-01$ \\
\hline $\mathrm{Cl}$ & E-04 & 7E-04 & $1.58 \mathrm{E}$ & $58 \mathrm{E}-04$ & 58E-04 & $1.58 \mathrm{E}-04$ & $2.11 \mathrm{E}-04$ \\
\hline $\mathrm{Ar}$ & $1 \mathrm{E}-02$ & $54 \mathrm{E}-02$ & $83 \mathrm{E}-02$ & 05E-01 & $.14 \mathrm{E}-01$ & $1.19 \mathrm{E}-01$ & $1.26 \mathrm{E}-01$ \\
\hline K & $1 \mathrm{E}-05$ & $6 \mathrm{E}-05$ & $7.58 \mathrm{E}-05$ & $59 \mathrm{E}-05$ & $7.60 \mathrm{E}-05$ & $7.60 \mathrm{E}-05$ & $7.90 \mathrm{E}-05$ \\
\hline $\mathrm{Ca}$ & $72 \mathrm{E}-02$ & 09E-02 & $8.08 \mathrm{E}-02$ & $9.66 \mathrm{E}-02$ & $.06 \mathrm{E}-01$ & $1.12 \mathrm{E}-01$ & $1.25 \mathrm{E}-01$ \\
\hline $\mathrm{Sc}$ & $75 \mathrm{E}-07$ & $21 \mathrm{E}-07$ & $7.40 \mathrm{E}-07$ & $55 \mathrm{E}-07$ & $7.65 \mathrm{E}-07$ & $7.71 \mathrm{E}-07$ & $8.68 \mathrm{E}-05$ \\
\hline $\mathrm{Ti}$ & $53 \mathrm{E}-05$ & $79 \mathrm{E}-05$ & $.98 \mathrm{E}-04$ & $5.24 \mathrm{E}-04$ & 7.00E-04 & 8.39E-04 & $2.56 \mathrm{E}-03$ \\
\hline V & $9 \mathrm{E}-07$ & 01E-06 & 06 & $18 \mathrm{E}-05$ & $.51 \mathrm{E}-05$ & $1.75 \mathrm{E}-05$ & $2.45 \mathrm{E}-05$ \\
\hline $\mathrm{Cr}$ & $5.39 \mathrm{E}-05$ & $5.90 \mathrm{E}-04$ & $3.33 \mathrm{E}-03$ & $6.59 \mathrm{E}-03$ & $9.47 \mathrm{E}-03$ & $1.20 \mathrm{E}-02$ & 2.31E-02 \\
\hline Mn & 55 & $1.20 \mathrm{E}-04$ & $3.5 \mathrm{~s}$ & -04 & $.07 \mathrm{E}-04$ & $9.67 \mathrm{E}-04$ & $1.59 \mathrm{E}-03$ \\
\hline $\mathrm{Fe}$ & & $2 \mathrm{E}-02$ & $5.23 \mathrm{H}$ & & $1.54 \mathrm{E}-01$ & $2.05 \mathrm{E}-01$ & $2.18 \mathrm{E}+00$ \\
\hline $\mathrm{Cc}$ & & $1.20 \mathrm{E}-06$ & & $1 \mathrm{E}-06$ & $1.21 \mathrm{E}-06$ & $1.21 \mathrm{E}-06$ & $9.32 \mathrm{E}-03$ \\
\hline $\mathrm{Ni}$ & $2.10 \mathrm{E}-04$ & $2.97 \mathrm{E}-04$ & $4.33 \mathrm{E}-04$ & $5.57 \mathrm{E}-04$ & $6.40 \mathrm{E}-04$ & $7.06 \mathrm{E}-04$ & $2.85 \mathrm{E}-02$ \\
\hline
\end{tabular}

